\title{
AC 2008-2170: MAKING THE CONNECTIONS: FACILITATING STUDENT INTEGRATION OF CHEMICAL ENGINEERING CONCEPTS INTO A COHERENT FRAMEWORK
}

\section{Rebecca Toghiani, Mississippi State University}

Dr. Rebecca K. Toghiani is an Associate Professor of Chemical Engineering at Mississippi State University. She received the 1996 Dow Outstanding New Faculty Award and the 2005

Outstanding Teaching Award from the ASEE Southeastern Section. A Grisham Master Teacher at Mississipi State, she is an inaugural member of the Bagley College of Engineering Academy of Distinguished Teachers. Her research activities focus on thermodynamics and separations.

\section{Adrienne Minerick, Mississippi State University}

Dr. Adrienne R. Minerick is an Assistant Professor of Chemical Engineering at Mississippi State University. She received her PhD and M.S. from the University of Notre Dame and B.S. from Michigan Technological University. Since joining MSU, Dr. Minerick has taught the graduate Chemical Engineering Math, Process Controls, Introduction to Chemical Engineering Freshman Seminar, and Heat Transfer Courses. In addition, she is an NSF CAREER Awaredee, has served as co-PI on an NSF REU site, PI on grants from NSF and DOE, and is the faculty advisor for MSU's chapter of the National Organization for the Professional Advancement of Black Chemists and Chemical Engineers (NOBCChE). Her research is in medical microdevice diagnostics \& dielectrophoresis.

\section{Keisha Walters, Mississippi State University}

Dr. Keisha Walters earned her $\mathrm{PhD}$ in Chemical Engineering in 2005 from Clemson University. She also holds an MS degree in Chemical Engineering and a BS degree in Biological Sciences from Clemson. Her work involves the surface modification of materials and the development of both stimuli-responsive and biomass-based polymeric materials. Central to her research in polymer and surface engineering is the design and synthesis of molecules with well-defined chemical functionality and molecular architecture. Fundamental research activities of her group include polymer synthesis, surface modification, grafting chemistries, and bulk and surface characterization. Current research includes $\mathrm{pH}$ - and temperature-responsive polymers, diagnostic sensor technologies, and the synthesis and surface modification of bioplastics. 


\title{
Making the Connections: Facilitating Student Integration of Chemical Engineering Concepts into a Coherent Framework
}

\begin{abstract}
One of the greatest challenges an instructor faces is helping his/her students to see the connections between material being covered in a particular class and that covered in previous courses or courses being taken concurrently. Opportunities exist within most engineering curricula to facilitate a student's ability to integrate the bits and pieces of knowledge they gain in one class with their existing knowledge base. Helping students to connect subject matter in one course to familiar concepts from fluids, thermodynamics, heat transfer, mass transfer, kinetics, and process control as well as from the foundation courses in mathematics, physics and chemistry can aid students in establishing their operational framework and improving their problem solving skills [Haile, 2000]. Through connecters placed throughout the prerequisite courses, instructors can facilitate student integration of material from different courses and important underlying concepts into a coherent framework. The presentation of these underlying concepts in different courses may be of a nature that masks their true connection to one another, thereby inhibiting the ability of students to connect and integrate a seemingly new concept into their knowledge base. In this paper, opportunities are presented where concept integration may be especially beneficial.
\end{abstract}

\section{Introduction}

In "The Thinker's Guide to Analytic Thinking", Elder and Paul [2007] define eight "Elements of Thought":

- Purpose

- Point of View

- Question at Issue

- Information

- Concepts

- Assumptions

- Interpretation and Inference

- Implications and Consequences

These elements are utilized by practicing engineers in their daily endeavors and allow them to successfully navigate technological challenges. The engineer must be able to draw on his/her knowledge base to arrive at a solution. How effectively that individual's ideas or concepts within that knowledge base are connected is essential to the engineer's ability to take these, make assumptions and inferences specific to a particular problem, and then generate a solution along with potential implications. The engineering student does not necessarily enter an undergraduate program with this innate ability; rather, it must be developed, through acquisition of knowledge of their chosen field, and through establishment of the interconnections and relationships of elements in their developing knowledge base.

Efforts to improve the conceptual understanding and concept integration abilities of undergraduate students have been the focus of substantial research during past years. For 
example, one component of the NSF-Funded Foundation Coalition (http://www.foundationcoalition.org) was development of concept inventories for a diverse set of engineering topics, including fluid mechanics, heat transfer and thermodynamics, based on the Force Concepts Inventory [Hestenes et al., 1992]. Falconer [2004, 2007] developed 'ConcepTests' for thermodynamics to both increase the conceptual understanding as well as challenge misconceptions they brought with them into the classroom. Schaffer and Schaffer [1999] describe the use of "Entrance Exams" as a mechanism to identify to students important concepts and topics that they will be responsible for in a subsequent course. Prince and Vigeant [2006] describe the use of inquiry-based activities to improve students' conceptual understanding. These are all excellent approaches focused on a common end result: improved understanding of concepts and their integration into a refined knowledge base that the student may readily draw upon and that continues to develop as the student moves through the chemical engineering curriculum.

A conventional engineering curriculum is quite different from the typical high school curriculum, in that there exists strong interdependence between multiple courses taken either simultaneously or sequentially in the undergraduate curriculum. A typical high school curriculum can be likened to streamlines in laminar flow. In this framework, each subject is isolated and distinct from another with little need for connection between topics or concepts (i.e., no mixing across streamlines!). For example, mathematics from one year to the next builds on knowledge obtained in previous mathematics courses; English from one year to the next builds on knowledge obtained in previous English courses. However, there is often little need to integrate concepts or ideas from mathematics to English or vice versa. Students arrive on the college campus with a compartmentalized view of subject areas and this influences their approach to subjects and courses they encounter on the college campus. By virtue of the necessity of serving many masters (the University core curriculum; the ABET requirements), the engineering curriculum is traditionally very lean on free electives, and very heavily concentrated in the sciences, engineering, and mathematics. This is especially true of chemical engineering curricula. With a recent reduction in the number of credit hours required for graduation (138 to 128), the chemical engineering curriculum at Mississippi State University (MSU) has only 12 hours of electives, but these are designated as a Chemical Engineering elective (3 hours), a chemistry elective ( 3 hours) and 6 hours of technical electives. What remains in the 128 hour curriculum are subject matter, content and concepts that are all considered essential elements of a chemical engineering curriculum by the faculty at this institution.

Once students arrive on campus, they are expected to navigate this focused and concentrated curriculum. The typical chemical engineering curriculum can be viewed as a pyramid, with the lower division courses in chemistry, mathematics, and physics providing the foundation of the pyramid. At the next level, courses introducing the language of chemical engineering including mass and energy balances, thermodynamics, and unit operations appear. These rely heavily on the strength of the foundation established during the freshman and sophomore level foundation courses. At the apex of the pyramid, one finds reactor design, process control, process design and plant design, all of which require a solid background in the previous courses and subject matter. 
Through connecters placed throughout the prerequisite courses, instructors have the opportunity to facilitate students in their integration of material from different courses and important underlying concepts into a coherent framework. The presentation of these underlying concepts in different courses may be of a nature that masks their true connection to one another, thereby inhibiting the ability of students to connect and integrate a seemingly new concept into their knowledge base. In this paper, opportunities are presented where concept integration may be especially beneficial.

\section{Opportunities in Thermodynamics}

One such opportunity occurs early in the semester when expressions for the enthalpy as a function of temperature and pressure are developed for gases and for liquids. Students at MSU have typically completed a fluid mechanics course prior to taking the second thermo course, and as a result, are well versed in the use and application of the Bernoulli equation for an isothermal, incompressible fluid, including pump work and frictional losses (simplified mechanical energy balance) [McCabe et al., 2005]:

$$
\frac{\mathrm{P}_{\mathrm{A}}}{\rho}+\mathrm{gZ} \mathrm{A}_{\mathrm{A}}+\frac{\alpha_{\mathrm{A}} \mathrm{V}_{\mathrm{A}}^{2}}{2}+\mathrm{W}_{\mathrm{P}}-\mathrm{h}_{\mathrm{fp}}=\frac{\mathrm{P}_{\mathrm{B}}}{\rho}+\mathrm{g} \mathrm{Z}_{\mathrm{B}}+\frac{\alpha_{\mathrm{B}} \mathrm{V}_{\mathrm{B}}^{2}}{2}+\mathrm{h}_{\mathrm{f}}
$$

where $P_{i}$ is the pressure, $V_{i}$ is the velocity, $\alpha_{i}$ is the kinetic energy correction factor and $Z_{i}$ is the elevation at point $i, \rho$ is the density, $g$ is acceleration due to gravity, $W_{P}$ is the pump work, $h_{f p}$ is the frictional losses associated with the pump, and $\mathrm{h}_{\mathrm{f}}$ are the frictional losses due to skin friction, sudden contractions and expansions, and pipe fittings. Students don't readily connect equation (1) with the energy balance they see in thermodynamics. They are most familiar with the energy balance for a single input, single output system operating at steady state in the form [Smith et al., 2005]

$$
\Delta \mathrm{H}+\Delta \mathrm{KE}+\Delta \mathrm{PE}=\mathrm{Q}+\mathrm{W}
$$

where $\mathrm{H}$ is enthalpy, $\mathrm{KE}$ is kinetic energy, $\mathrm{PE}$ is potential energy, $\mathrm{Q}$ is heat transfer, and $\mathrm{W}$ is shaft work. The connection between the elevation terms and the velocity terms in equation (1) with the change in potential energy and change in kinetic energy in equation (2), respectively, is fairly easy for the student to make, as is the pump work, $\mathrm{W}_{\mathrm{P}}$, with the shaft work, W. However, the connection between the remaining terms is not readily apparent. The frictional losses, $\mathrm{h}_{\mathrm{fp}}$ and $\mathrm{h}_{\mathrm{f}}$, are the lost work, and this energy is dissipated as heat (Q). Students rarely identify this connection. The remaining term in equation (2) is the enthalpy change, $\Delta \mathrm{H}$. The enthalpy as a function of temperature and pressure is written

$$
\mathrm{dH}=\left(\frac{\partial \mathrm{H}}{\partial \mathrm{T}}\right)_{\mathrm{P}} \mathrm{dT}+\left(\frac{\partial \mathrm{H}}{\partial \mathrm{P}}\right)_{\mathrm{T}} \mathrm{dP}=\mathrm{C}_{\mathrm{p}} \mathrm{dT}+\left[\mathrm{V}-\mathrm{T}\left(\frac{\partial \mathrm{V}}{\partial \mathrm{T}}\right)_{\mathrm{P}}\right] \mathrm{dP}=\mathrm{C}_{\mathrm{p}} \mathrm{dT}+\mathrm{V}[1-\beta \mathrm{T}] \mathrm{dP}
$$

where $C_{p}$ is the constant pressure heat capacity, and $\beta$ is the volume expansivity of the fluid. For many liquids, the assumption that the fluid is incompressible is reasonable and in thermodynamics, this translates to both the isothermal compressibility and the volume expansivity being set to zero. The constant pressure and constant volume heat capacities are 
equal for an incompressible liquid, and often denoted as C, a specific heat. Thus, equation (3) simplifies to:

$$
\mathrm{dH}=\mathrm{CdT}+\mathrm{VdP}
$$

For isothermal operation, the only contribution to the enthalpy the second term in equation (4). The specific volume is independent of temperature and pressure for the incompressible fluid; thus, integration yields:

$$
\Delta \mathrm{H}=\mathrm{V} \Delta \mathrm{P}=\frac{\Delta \mathrm{P}}{\rho}
$$

where specific volume has been replaced by reciprocal density. Thus, the $\Delta \mathrm{P} / \rho$ term in the Bernoulli equation is simply the enthalpy change due to pressure for the isothermal, incompressible fluid. This is a connection that the majority of students would not readily make, but helps to connect what they have seen previously in fluid mechanics with what they are seeing in thermodynamics.

Another opportunity presents itself when phase equilibrium is examined. Students have covered the use of $\mathrm{P}-\mathrm{x}_{1}-\mathrm{y}_{1}$ and $\mathrm{T}-\mathrm{x}_{1}-\mathrm{y}_{1}$ diagrams in their introductory mass and energy balance course, where the focus is primarily ideal systems. Many of the chemical systems encountered in industry exhibit non-idealities and the impact of these non-idealities may not be readily connected to changes in the bubble point and dew point curves on the $\mathrm{P}-\mathrm{x}_{1}-\mathrm{y}_{1}$ or $\mathrm{T}-\mathrm{x}_{1}-\mathrm{y}_{1}$ diagram. Non-ideal liquid phase behavior is covered during the second thermodynamics course at MSU. One usually starts with the $\mathrm{P}-\mathrm{x}_{1}-\mathrm{y}_{1}$ diagram for a system following Raoult's law, with its characteristic linear bubble point curve $\left(\mathrm{P}-\mathrm{x}_{1}\right)$ :

$$
\mathrm{P}_{\mathrm{BP}}=\mathrm{P}_{1}^{\mathrm{sat}} \mathrm{x}_{1}+\mathrm{P}_{2}^{\mathrm{sat}} \mathrm{x}_{2}=\left(\mathrm{P}_{1}^{\mathrm{sat}}-\mathrm{P}_{2}^{\mathrm{sat}}\right) \mathrm{x}_{1}+\mathrm{P}_{2}^{\text {sat }}
$$

The introduction of the activity coefficient, $\gamma_{i}$, results in the Modified Raoult's law. For the determination of bubble point pressure, this results in:

$$
\mathrm{P}_{\mathrm{BP}}=\gamma_{1} \mathrm{P}_{1}^{\mathrm{sat}} \mathrm{x}_{1}+\gamma_{2} \mathrm{P}_{2}^{\mathrm{sat}} \mathrm{x}_{2}
$$

Systems exhibiting positive deviations from Raoult's law have $\gamma_{i}>1$, while those exhibiting negative deviations from Raoult's law have $\gamma_{i}<1$. Students generally recognize that equation (6) is linear in $\mathrm{x}_{1}$. An interesting in-class exercise is to have each student sketch the bubble point curve corresponding to a system with mild positive deviations from Raoult's law and a system with mild negative deviations from Raoult's law (with nothing more than the relationship shown in equation (7) - i.e., no numerical values). Students usually recognize that positive deviations or negative deviations will result in a bubble point curve with curvature (no longer linear, due to dependence of activity coefficients on composition); however, recognition that deviations from the bubble point curve for Raoult's law will be much smaller near the pure component endpoints, and much larger for mixtures where both compounds are present in appreciable amounts often eludes them. The connection between this behavior and the magnitude of the contributions from 
each term in equation (7) when one is near a pure component limit or in a region where both components are present in appreciable amounts can be made during classroom discussion. Students also recognize that positive deviations result in a bubble point curve that lies above that for Raoult's law and that negative deviations result in a dew point curve that lies below that for Raoult's law. General recognition of ideal/non-ideal behavior by examination of the bubble point curve on a $\mathrm{P}-\mathrm{x}_{1}-\mathrm{y}_{1}$ diagram is now a tool that students can readily use when needed.

When deviations from ideal behavior are substantial, the system may exhibit an azeotrope. Identification of the azeotrope is easy when a $\mathrm{P}-\mathrm{x}_{1}-\mathrm{y}_{1}$ or $\mathrm{T}-\mathrm{x}_{1}-\mathrm{y}_{1}$ diagram is available for the system. From equation (7), one could even determine the location of the azeotrope by taking the derivative of $\mathrm{P}_{\mathrm{BP}}$ with respect to $\mathrm{x}_{1}$ and finding the extrema. This most likely would require numerical solution (i.e., exploitation of SOLVER in Excel) and students gain very little from the exercise, short of having to differentiate a perhaps complex expression for each of the $\gamma_{i}$ with respect to $\mathrm{x}_{1}$ ). They could also evaluate the second derivative and determine whether it is a maximum pressure or minimum pressure azeotrope. However, one may also deduce the presence of an azeotrope through examination of the relative volatility when a diagram is not available [Smith et al., 2005]. Given information about the non-ideal behavior in the system (either infinite dilution activity coefficients, or binary parameters for a specific activity coefficient model), one can evaluate the relative volatility as a function of composition:

$$
\alpha_{12}=\frac{\mathrm{y}_{1} / \mathrm{x}_{1}}{\mathrm{y}_{2} / \mathrm{x}_{2}}=\frac{\gamma_{1} \mathrm{P}_{1}^{\mathrm{sat}}}{\gamma_{2} \mathrm{P}_{2}^{\text {sat }}}
$$

The relative volatility is a smooth function of composition [Smith et al., 2005]. As a result, examination of the limiting behavior of the relative volatility at the pure component endpoints allows one to readily affirm or deny the presence of an azeotrope.

$$
\begin{aligned}
& \lim _{\mathrm{x}_{1} \rightarrow 0} \frac{\gamma_{1} \mathrm{P}_{1}^{\text {sat }}}{\gamma_{2} \mathrm{P}_{2}^{\text {sat }}}=\frac{\gamma_{1}^{\infty} \mathrm{P}_{1}^{\text {sat }}}{(1) \mathrm{P}_{2}^{\text {sat }}}=\frac{\gamma_{1}^{\infty} \mathrm{P}_{1}^{\text {sat }}}{\mathrm{P}_{2}^{\text {sat }}} \\
& \lim _{\mathrm{x}_{1} \rightarrow 1} \frac{\gamma_{1} \mathrm{P}_{1}^{\text {sat }}}{\gamma_{2} \mathrm{P}_{2}^{\text {sat }}}=\frac{(1) \mathrm{P}_{1}^{\text {sat }}}{\gamma_{2}^{\infty} \mathrm{P}_{2}^{\text {sat }}}=\frac{\mathrm{P}_{1}^{\text {sat }}}{\gamma_{2}^{\infty} \mathrm{P}_{2}^{\text {sat }}}
\end{aligned}
$$

If both of these limits are greater than 1 or both are less than 1 , then no azeotrope is present in the system. If one limit is greater than 1 , and the other limit is less than 1 , then at some intermediate composition, $0<\mathrm{x}_{1}<1$, the relative volatility passes through a value of 1 , and it is confirmed that the system possesses an azeotrope. Determination of whether the azeotrope is of the minimum pressure or maximum pressure type requires additional computations. However, if a bubble point pressure at some intermediate composition is greater than either pure component vapor pressure, the azeotrope is of the maximum pressure type, while if it is less than either pure component vapor pressure, the azeotrope is of the minimum pressure type. If the computed bubble point pressure at the intermediate composition is between the pure component vapor pressures, further computations are required to deduce the type of azeotrope present. 


\section{Opportunities in Heat Transfer}

Students enrolled in heat transfer at Mississippi State University have generally had four semesters (12 credit hours) of calculus including functions, limits, definite and indefinite integration, vectors, infinite series, and multivariate calculus. Despite the considerable attention calculus receives in the curriculum prior to the heat transfer course, there is a significant lack of connection between previously learned math concepts and manipulations and utilization of math in defining physical systems and engineering applications. In mathematics courses, the starting equations are simply 'given' and the student learns to successfully perform operations on these equations. In this theoretical/isolated approach, the starting equations are not derived. Therefore, in a subsequent engineering course, such as heat transfer, there is often a disconnect for the students between a physical process, first principles, such as conservation laws, derivation of governing equations for the process, and corresponding graphical representations.

One of the first instances where the heat transfer instructor has the opportunity to bridge this lack of integration between physical systems and (previously learned) mathematical principles is with shell energy balances (differential control volume energy analyses) ${ }^{1}$. Here there is an opportunity to show a student (perhaps for the first time) how to derive the governing equations for a system. This involves not only reviewing the definition of a differential equation and methods for deriving differential equations, but also the energy balance concept. Once the governing equation is derived, the same mathematical manipulations learned in calculus can be performed; however, the physical meanings of these manipulations must be explicitly pointed out. What does the derivative or integral 'tell' us about our system? The value of these concepts is well-received by the students when it is shown that performing the actual derivative or integral is not always necessary. All that may be needed to 'solve the problem' is recognizing simple mathematical relationships. It should be noted that the expectation of "using calculus" in their chemical engineering courses is usually met by many confused faces and quickly followed by grimaces and groans. This reaction further supports the idea that calculus concepts were learned only for their calculus courses, without an expectation of future use.

A related issue arises in the use of boundary conditions in either setting the bounds for definite integration or to solve for indefinite integration constants. While the actual mathematical mechanics are not foreign to them, having the students define and use appropriate expressions related to the physical system (e.g., constant wall temperature, constant heat flux, maximum/minimum heat flux, adiabatic wall) is often a challenging task. This again speaks to a deficiency in linkages between physical concepts and mathematics.

One of the first equations learned in heat transfer is Fourier's Law of Conduction [Incopera et al., 2007]:

$$
\frac{\mathrm{Q}}{\mathrm{A}}=-\mathrm{k} \frac{\mathrm{dT}}{\mathrm{dx}}
$$

While students see this as a simple equation that they can use to find unknown quantities (e.g., heat flux, heat flow, temperature), they often have difficulty seeing how to use this equation

\footnotetext{
${ }^{1}$ Incidentally, by pointing out to the students that a control volume energy analysis is just an energy balance is a way to tie back into concepts learned in their mass and energy balance and thermodynamics courses.
} 
'conceptually' to recognize relationships. For instance, recognition of proportional (e.g., Q $\alpha$ $\Delta \mathrm{T} ; \mathrm{Q} \alpha \mathrm{A}$ ) and inversely proportional (e.g., q $\alpha 1 / \mathrm{R}=\Delta \mathrm{x} / \mathrm{k}$ ) relationships allows for comparison of heat transfer rates in two geometrically identical systems with differing thermal conductivities (k) at a glance. This simple equation can also be used to reemphasize the physical meaning of derivatives in engineering systems. For example, students should be able to examine the slope of a given temperature profile (such as those given in Figure 1) to gain insight into the system's heat flow behavior (q $\alpha \mathrm{dT} / \mathrm{dx}$ ). This same process can work in reverse. How does one know how to draw a temperature profile? Is the temperature profile linear? What is the slope? How does the slope change as a certain boundary is approached?
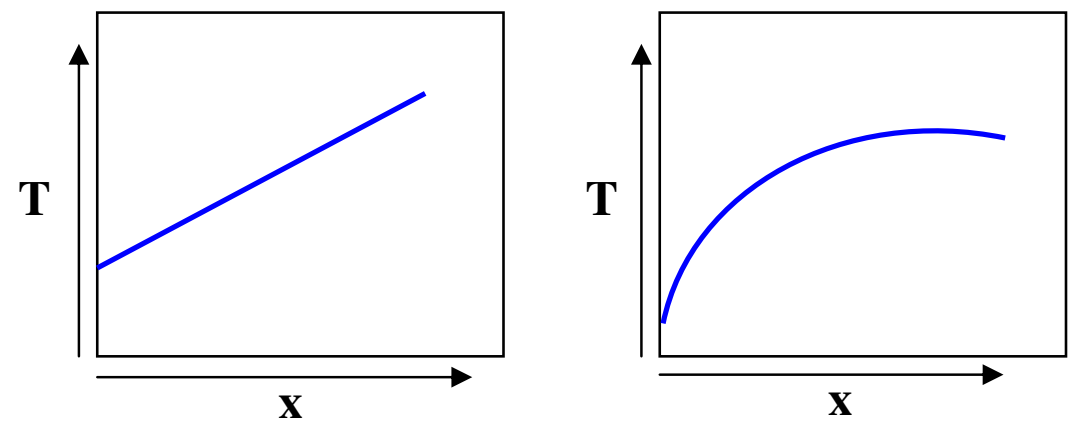

Figure 1. Two temperature profiles used to demonstrate interpretation of temperature profiles.

Many other concepts can be gleaned from this simple equation. Fourier's Law provides confirmation that the $2^{\text {nd }}$ Law of thermodynamics is not being violated; heat does indeed flow "downhill". One can also determine where maximum and minimum heat loss occurs in the system by examining the slope maxima and minima. Another demonstration of relationship recognition with Fourier's Law is the examination of the T-x slope to yield relative thermal conductivities.

Another opportunity to establish a connection with material studied previously in general chemistry is when the concepts of sensible heat and latent heat are examined in the heat transfer course. During their general chemistry course, this material is often presented in the form of T-Q diagrams and discussion is limited to pure species. A typical T-Q diagram that students are familiar with is shown in Figure 2. 


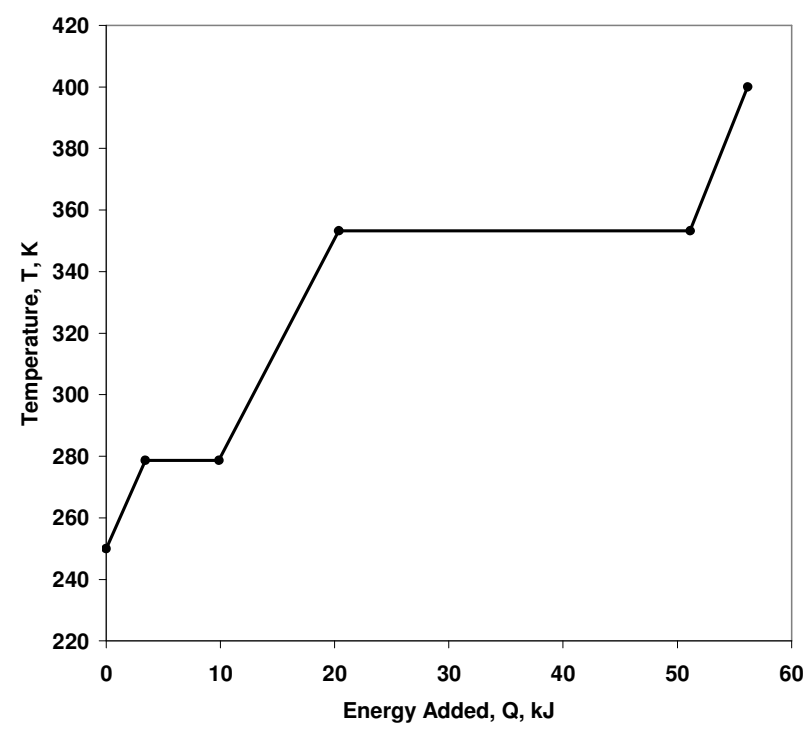

Figure 2. Typical T-Q Diagram from General Chemistry

From this, discussions regarding sensible heat effects $\left(\mathrm{Q}=\mathrm{mC}_{\mathrm{P}} \Delta \mathrm{T}\right)$ versus latent heat effects $(\mathrm{Q}$ $=\mathrm{m} \Delta \mathrm{H}^{\mathrm{fus}}, \mathrm{m} \Delta \mathrm{H}^{\mathrm{vap}}$ ) can commence. The magnitude of energy required to effect a phase change, in particular, vaporization, compared to that required to effect a change in temperature is readily apparent from Figure 2. Yet, the how is what has been focused on during general chemistry, rather than the why. For example, why is more energy required to bring about a phase change (latent heat effect) compared to a temperature change (sensible heat effect)? What can be gleaned from examination of the slopes on the T-Q diagram regarding the specific heats of a solid versus a liquid versus a vapor? Why does it take so much more energy to vaporize a material compared to melting of the same substance? The connection with thermodynamics can be made here as the energy requirement is related to movement from one state to a state of greater disorder (a state of higher entropy). Why doesn't the temperature change during the phase change process? The connection to what students are often studying concurrently in thermodynamics can be made as students realize that the Gibbs' phase rule governs this - for a pure component with two phases, there is one degree of freedom - this is independent of whether the subject matter is heat transfer or thermodynamics!

\section{Opportunities in Separations}

In the separations course in most chemical engineering curriculums, distillation, gas absorption and stripping and liquid extraction are studied in addition to other separation processes. For a student, one readily identified connection between these three important separation processes is that they are all typically carried out in a countercurrent continuous contactor. All four rely on a separating agent; for distillation, the basis of separation is due to an energy-separating agent, while for absorption/stripping and extraction, the basis of separation is due to a mass-separating agent. One of the earliest discussions for any of these processes covers limiting operating conditions [Wankat, 2006]. For gas absorption, this is a minimum liquid to gas ratio, (L/G) $\min$, corresponding to the minimum amount of liquid solvent that must be used to accomplish removal of a specific amount of a contaminant from the gas phase. For stripping, this is a maximum liquid to gas ratio, $(\mathrm{L} / \mathrm{G})_{\max }$, corresponding to the minimum amount of gas required to 
accomplish removal of a specific amount of a contaminant from the liquid phase. For extraction, this is a maximum diluent to solvent ratio, $\left(\mathrm{F}_{\mathrm{D}} / \mathrm{F}_{\mathrm{S}}\right)_{\max }$, corresponding to the minimum amount of solvent required to accomplish removal of a specific amount of a contaminant from the diluent phase. The connection between these is often not immediately grasped by the student. Recognition that each of these ratios corresponds to a minimum requirement of the mass separating agent allows the student to then make the connection to process economics. In distillation, the minimum reflux ratio is the ratio of liquid to vapor flowrate, $(\mathrm{L} / \mathrm{V})_{\min }$, that can be used to accomplished a given separation, for a specified feed composition and quality. The minimum reflux ratio corresponds to the minimum requirement of the separating agent - in this case, energy supplied to the reboiler in a distillation column. The connection between these that one is determining the minimum requirement for the given separating agent - is not readily apparent to the student; in fact, this connection was not readily apparent to one of the authors, until they taught the course!

\section{Opportunities in Reactor Design}

In reactor design, one opportunity to connect concepts from earlier chemistry, mathematics and thermodynamics courses presents itself when examining temperature and conversion profiles for a plug flow reactor, operating under three different modes: 1) isothermally; 2) adiabatically; and 3) non-isothermal/non-adiabatically (i.e., NINA - with prescribed heat transfer). Students are very adept with available numerical software packages and can solve sets of equations such as equations (12)-(14) [Fogler, 2005] to produce wonderful plots of the temperature and conversion as a function of reactor volume, as shown in Figure 3.

$$
\begin{aligned}
& \mathrm{r}_{\mathrm{A}}=-\mathrm{kC}_{\mathrm{A}} \\
& \frac{\mathrm{dX}}{\mathrm{dV}}=-\frac{\mathrm{r}_{\mathrm{A}}}{\mathrm{F}_{\mathrm{A} 0}} \\
& \frac{\mathrm{dT}}{\mathrm{dV}}=\frac{\mathrm{U}_{\mathrm{a}}\left(\mathrm{T}_{\mathrm{a}}-\mathrm{T}\right)+\left(-\Delta \mathrm{H}_{\mathrm{rX}}\right)\left(-\mathrm{r}_{\mathrm{A}}\right)}{\sum \mathrm{F}_{\mathrm{i}} \mathrm{C}_{\mathrm{pi}}}
\end{aligned}
$$
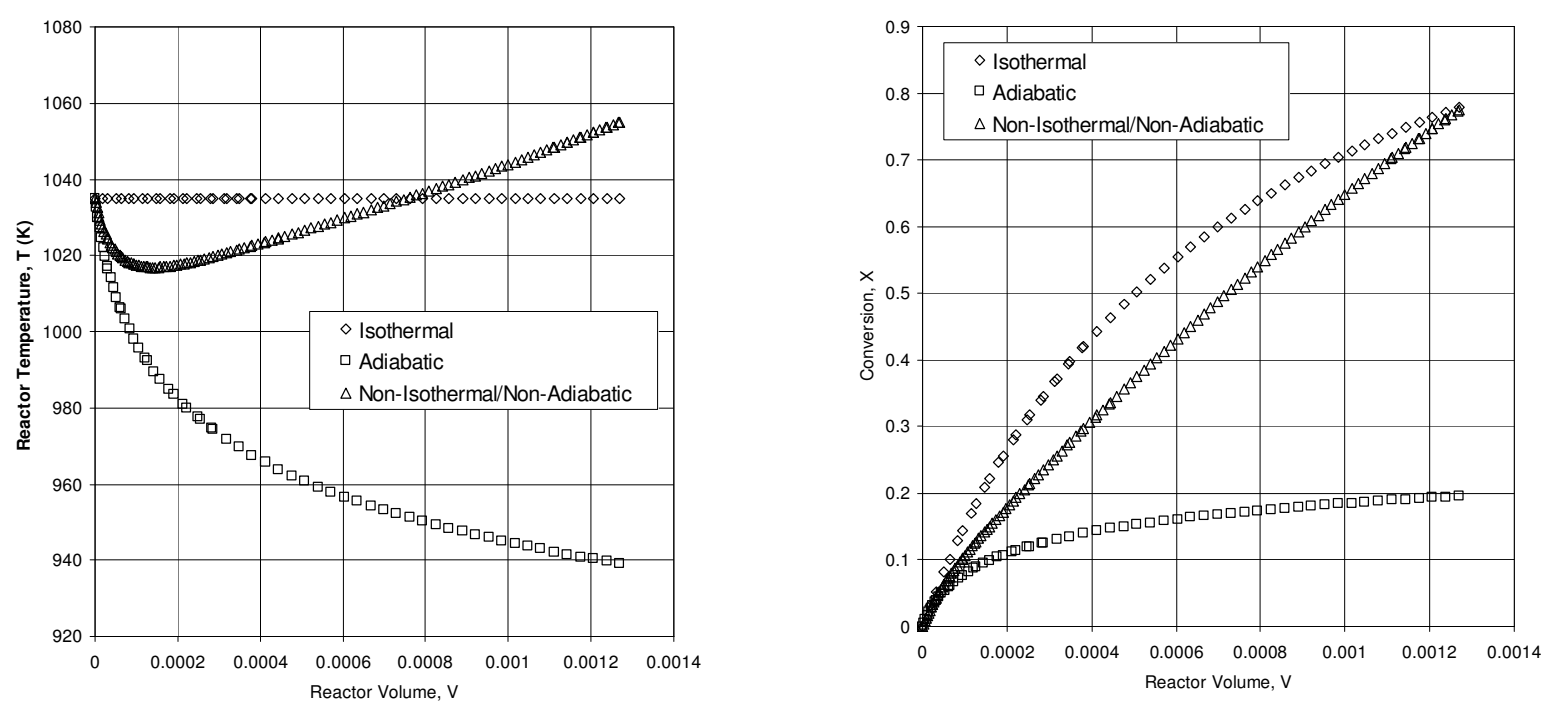

Figure 3. Temperature and Conversion Profiles for Different Modes of Operation 
Comparison plots such as these provide a prime opportunity for establishing connections between important concepts. A homework problem where plots such as these are provided along with the relevant governing equations and a set of probing questions, but with no numerical values and no chemicals identified, are wonderful for helping students strengthen their understanding of heat effects in chemical reactors. A series of questions might include:

1) Is the reaction endothermic or exothermic? Reaction is endothermic; the temperature profile shows a significant decrease as the reacting mixture moves through the reactor. Since the reactor is operating adiabatically, the only explanation is that the energy required for the reaction is being supplied by the reacting mixture.

2) Using the governing equations, explain the drop in conversion for adiabatic operation as compared to isothermal operation. The conversion in the reactor is influenced by the rate constant, and by the concentration of reactants. With adiabatic operation for this endothermic reaction, the drop in temperature results in a drop in the reaction rate constant, thereby reducing the rate of reaction, and lowering the conversion. As the reaction proceeds, reactants are converted to products. The influence of reactant concentrations will be determined by the reaction order with respect to each reactant. If the reaction is zero order in reactants, then reactant concentrations will not impact the reaction rate; however, if the reaction rate is a function of a reactant concentration ( $1^{\text {st }}$ order as shown.), then a drop in reactant concentration as the reaction proceeds will reduce the reaction rate, thereby, lowering the incremental conversion.

3) Identify at least one disadvantage of isothermal operation, using information from the plots. Operation under isothermal conditions results in the reaction rate constant remaining a constant. However, the general shape of the $X(V)$ curve for isothermal operation shows that the rate at which conversion, $X$, is changing with reactor volume, $V$, is decreasing as reactor volume increases.

4) Using the energy balance, explain the shape of the temperature profile for NINA operation. In non-isothermal, non-adiabatic operation, the temperature profile passes through a minimum. At volumes less than that corresponding to the minimum temperature, the rate of reaction is high, leading to a drop in temperature in the reacting mixture, because the energy supplied from $U_{a}\left(T_{a}-T\right)$ is not sufficient to supply the necessary energy to drive the reaction. At the minimum, the two terms, $U_{a}\left(T_{a}-T\right)$ and $\left(-\Delta H_{r x}\right)\left(-r_{A}\right)$ are perfectly balanced. At volumes greater than that corresponding to the minimum temperature, the energy supplied from the external source, $U_{a}\left(T_{a}-T\right)$ is more than sufficient to supply the required energy to drive the reaction. The energy supplied over and above this requirement goes to increase the temperature of the reacting mixture, leading to increased reaction rate constant.

5) Using the energy balance, explain the shape of the temperature profile for adiabatic operation. For adiabatic operation, all of the energy required by the reaction must either be supplied by the reacting mixture (endothermic reaction) or absorbed by the reacting mixture (exothermic reaction). The drop in temperature realized in the temperature profile for adiabatic operation indicates that this is an endothermic reaction. The change in the slope of the temperature profile (initially, a rapid change in $d T / d V)$ as the reacting mixture moves through the reactor is related to the relative amount of reaction taking place in each given volume element; at the inlet to the reactor, reactant concentrations are high, as is temperature; thus, the rate of reaction 
is highest at the inlet to the reactor. As the reacting mixture moves through the reactor, the temperature drops due to decreased concentrations of reactants, and this, coupled with the decrease in temperature as energy required to drive the endothermic reaction is drawn from the reacting mixture, results in a lower reaction rate.

6) The NINA temperature profile passes through a minimum. Identify the dominant term in the energy balance at a volume less that the volume corresponding to the minimum temperature; identify the dominant term in the energy balance at a volume greater than the volume corresponding to the minimum temperature. Explain why the temperature profile exhibits a minimum. In the energy balance, the minimum temperature corresponds to a slope of zero $(d T / d V=0)$. At volumes less than that corresponding to the minimum temperature, the dominant term is the $\left(-\Delta H_{r x}\right)\left(-r_{A}\right)$ term. At volumes greater than that corresponding to the minimum temperature, the dominant term is $U_{a}\left(T_{a}-T\right)$. The temperature profile exhibits a minimum because at this point, the energy required by the reacting mixture to drive the reaction at the prescribed rate is exactly balanced by the energy supplied by the external heating medium.

7) Qualitatively describe how would the profiles change if the overall heat transfer coefficient were increased by 50\%? How would the profiles change if the temperature of the heat transfer medium, $\mathrm{T}_{\mathrm{a}}$, were changed (increased or decreased)? If overall heat transfer coefficient or temperature of heat transfer medium were increased, the impact on the profile would be similar, with a shift in the minimum to a smaller volume. If the temperature of the heat transfer medium were decreased, the minimum in the profile would be shifted to larger volume and the minimum reactor temperature would actually be lower than the case shown.

Questions such as these require the students to draw on their knowledge base and gather pertinent concepts from general chemistry and thermodynamics (endothermic versus exothermic, heat of reaction), heat transfer (adiabatic, isothermal, NINA operation; impact of $U, T_{a}$ ), calculus (slope of function, minimum in function), and differential equations.

\section{Opportunities in Process Control}

Process Control is typically a senior-level capstone class, so students usually have had all of their thermo, mass and heat transfer when entering this class. At Mississippi State University, they take Reactor Design before Process Control because continuous stirred tank reactors (CSTRs) are fun problems to illustrate composition control concepts. Furthermore, process controls relies heavily on the student's math background including a heavy emphasis on differential equations. A number of undergraduate texts have eliminated differential forms of equations for heat transfer, mass transfer, and reactor design. As a result, the student's mathematical skills can be lacking when entering Process Control.

One of the fundamental concepts that students need a solid understanding of for process controls is dynamic mass balances. These are covered in Chapter 11 in Felder and Rousseau [2005]. Due to limited time in the semester and competing (but equally important concepts), this chapter is sometimes not covered in a Mass and Energy Balances course. One can start by making the connection to the well-ingrained expression: 


$$
\text { Mass In }- \text { Mass Out }+ \text { Generation }- \text { Consumption }=\text { Accumulation }
$$

For the straightforward example of pumping fluid into or out of a holding tank, students sometimes need to be reminded of the definition of a function, $F_{\text {in }}(t)$ versus $F_{\text {in }}$. Both volumetric flows have the same units, which are volume per time, but the connection that a flow rate is not always a constant with respect to time is uncommon to them and they can initially struggle with the concept. Further, when simplifying the general balance equation for this system, many students will automatically reduce to:

$$
\text { Mass In = Mass Out }
$$

They long ago accepted this as an absolute rule and mentally skip over that they assumed accumulation was zero to have simplified to this point; it has incorrectly become synonymous in their minds with the fundamental chemistry principle that mass can neither be created nor destroyed. However, upon pointing out that a cyclical, time-dependent pump on the inlet stream to a tank is not necessarily synchronized with a time-dependent pump on the outlet stream, students can write:

$$
F_{\text {in }}(t)-F_{\text {out }}(t)=\text { accumulation }
$$

At this point, the connections to calculus and differential equations are rusty enough, they don't typically demonstrate how to represent a rate, even though many can physically describe what will happen in the tank. They recognize that volume will change in the tank and when asked to write this mathematically, a significant portion will then write $\mathrm{V}(\mathrm{t})$. By questioning whether the units match or asking them to remember how they mathematically represented a velocity (i.e. rate) in calculus, many will then arrive at the following:

$$
F_{\text {in }}(t)-F_{\text {out }}(t)=\frac{d V}{d t}
$$

When asked to solve, a few will make the connection that if the outlet pipe for the flow out is located at the bottom of the tank and the driving force for fluid leaving is hydrostatic head, they start digging for an appropriate equation. Depending on assumptions, a handful of expressions can represent flow out as a function of height $F_{\text {out }}(t)=f(h)$. Height is related back to volume easily provided the tank area is constant. Assuming the pressure drop from the fluid is primary due to the constriction from the tank to the pipe, a simple expression for flow can be used with $\mathrm{k}_{\mathrm{f}}$ as a friction factor [Marlin, 2000]:

$$
F_{\text {out }}(t)=k_{f} \sqrt{h}
$$

The resulting dynamic mass balance differential equation is:

$$
F_{i n}(t)-k_{f} \sqrt{h(t)}=A \frac{d h}{d t}
$$


This is then the perfect stepping stone to tie back to differential equation knowledge including homogeneity, linearity, and order. Recognizing nonlinearity and linearization of such terms ties back to fundamental knowledge as well - e.g. the Taylor series. Furthermore, students revisit ordinary differential equations including separable equations and integrating factors so that they appreciate the Laplace transform tool when it is introduced.

\section{Summary}

There are a number of opportunities in courses throughout the chemical engineering curriculum that can be used to facilitate integration of concepts from earlier foundation courses in mathematics, chemistry, physics and chemical engineering. The ability of a student to integrate knowledge gained into a coherent framework is enhanced by faculty actively fostering this integration by relating specific concepts in their course to subjects/concepts/course materials from courses students have previously completed.

\section{References}

Elder, 'L., Paul, R., The Thinker's Guide to Analytic Thinking, (The Foundation for Critical Thinking, www.criticalthinking.org, 2007).

Falconer, J.L., "Use of ConcepTests and Instant Feedback in Thermodynamics", Chemical Engineering Education, $\underline{38}$, 64-, (2004).

Falconer, J.L., "ConcepTests for a Thermodynamics Course", Chemical Engineering Education, 41(2), 107-114, (2007).

Felder, R.M, Rousseau, R.W., Elementary Principles of Chemical Processes, $\left(3^{\text {rd }}\right.$ Edition, Wiley $\&$ Sons, Inc., New York, NY: 2005).

Fogler, H.S., Elements of Chemical Reaction Engineering, $\left(4^{\text {th }}\right.$ edition, Prentice Hall PTR, Englewood Cliffs, NJ: 2005).

Haile, J.M., "Toward Technical Understanding. Part 4. A General Hierarchy Based on the Evolution of Cognition," Chemical Engineering Education, 34, 48-54 (2000).

Hestenes, D., Wells, M., Swackhamer, G., "Force Concept Inventory", The Physics Teacher, 30(3), 141-151, (1992).

Incropera, F.P., Dewitt, D.P., Bergman, T.L., Lavine, A.S., Introduction to Heat Transfer, $\left(5^{\text {th }}\right.$ edition, John Wiley \& Sons: 2007).

Marlin, T.E., Process Control: Designing Processes and Control Systems for Dynamic Performance, ( $2^{\text {nd }}$ edition, McGraw-Hill, New York, NY: 2000).

McCabe, W.L., Smith, J.C., Harriott, P., Unit Operations of Chemical Engineering, $7^{\text {th }}$ edition, McGraw-Hill Higher Education, New York, NY: 2005).

Prince, M., Vigeant, M., "Using Inquiry-Based Activities to Promote Understanding of Critical Engineering Concepts", 2006 ASEE Conference Proceedings.

Smith, J.M., van Ness, H.C., Abbott, M.M., Introduction to Chemical Engineering Thermodynamics, $\left(7^{\text {th }}\right.$ edition, McGraw-Hill Higher Education, New York, NY: 2005).

Wankat, P.C., Separation Process Engineering, $\left(2^{\text {nd }}\right.$ Edition, Prentice Hall PTR, Englewood Cliffs, NJ: 2006). 